\title{
1 Decision-support method for profitable residential energy retrofitting based 2 on energy-related occupant behaviour.
}

3

4 Abstract

Low-carbon energy retrofitting in buildings plays an important role because $75 \%$ of European buildings are considered inefficient and more than $40 \%$ are currently over 50 years old. The economic reinvestment of energy retrofit actions through reduced energy bills, as energy directives promote, greatly depends upon the energy consumption patterns. In support of the decision-making process towards a low-carbon energy transition in multi-family buildings, this paper introduces a novel assessment method that evaluates the profitability of energy efficiency measures, according to standard operating conditions derived from energy performance certificate procedures and real occupant energy consumption scenarios, through a parametric analysis. The aim is to assess the real energy and economic savings of retrofitting actions, depending on different energy-related occupant scenarios, and to enable comparisons with other buildings, providing a valuable model to identify the most feasible and low-carbon energy strategies in residential energy retrofitting. A Spanish multi-family building from 1942 is taken as the reference case study. The results show that energy savings for dwellings vary up to $80 \%$, and the net present value per dwelling differs by up to $20,000 €$ between different energy consumption patterns. The most appropriate energy efficiency measures according to low, medium or high consumption scenarios are highlighted.

Keywords: energy renovation; low-carbon energy; occupant behaviour; consumption scenarios; decision-making; multi-family buildings. 
NOMENCLATURE

a operation year

$C_{f} \quad$ annual cash flow

COP coefficient of performance

DHW domestic hot water

ED energy demand $\left(\mathrm{kWh} / \mathrm{m}^{2} \mathrm{a}\right)$

EEM energy efficiency measure

EER energy efficiency ratio

EIFS exterior insulation and finishing system

EPBD Energy Performance of Building Directive

EPC Energy Performance Certificates

EPS expanded polystyrene insulation

HP heat pump

IC investment cost $(€)$

NPV net present value $(€)$

OECD Organisation for Economic Co-operation and Development

PBP payback period

PEC primary energy consumption

SHGC seasonal heat gain coefficient of shading devices

$r \quad$ discount rate

TB thermal-break

$\mathrm{U}$ thermal transmittance $\left(\mathrm{W} / \mathrm{m}^{2} \mathrm{~K}\right)$

XPS extruded polystyrene 


\section{INTRODUCTION}

The building sector is responsible for $36 \%$ of global final energy consumption and more than 55\% of the electricity demand (International Energy Agency, 2017, 2013a). In the European Union, this sector is responsible for approximately $40 \%$ of energy consumption and $36 \%$ of $\mathrm{CO}_{2}$ emissions (European Commission, 2018, 2014), of which $70 \%$ corresponds to heating, cooling and domestic hot water (International Energy Agency, 2017, 2013a), being mostly fossil fuels based (European Commission, 2016).

European statements consider that almost $75 \%$ of building stock is energy inefficient (European Commission, 2015a). Regarding building aging, more than $40 \%$ of current housing stock are over 50 years old (Aksoezen et al., 2015; International Energy Agency, 2017) and 75\% of buildings anticipated for 2050 are already built, in the case of the European Union and OECD member countries (Cuchí and Sweatman, 2013; International Energy Agency, 2013b). Therefore, the energy renovation of existing buildings has a huge potential to lead to significant energy savings (Arumägi et al., 2017).

Following these guidelines, European policies aim to support low-carbon energy transition through sustainable renovation strategies. The European Energy Performance of Buildings Directive (EPBD) (European Commission, 2018) underlines the need to implement new methods and protocols for energy retrofitting processes in the building stock, ensuring viable and efficient operations to achieve environmental targets, as well as to improve the quality of life of citizens (Thuvander et al., 2012). Moreover, EPBD considers that financing through energy bill savings is the main option to finance the energy retrofitting process (European Commission, 2018). However, it is also essential to consider the users' energy consumption attitude, and each socioeconomic context, to achieve sustainable and efficient interventions (Heiskanen et al., 2013). Lizana et al. (2016) stated that economic savings, related to energy bills, might not be enough for end-users to support energy retrofitting at current energy prices. In addition, as pointed by Vilches et al. (2017), families with low income levels represent an important barrier for carrying out retrofitting actions.

European standards and regulations are developing energy performance calculation methods to support the EPBD, focused on enabling comparisons with other buildings and evaluating real energy and economic savings in building retrofitting processes. The most common are the energy assessment methods, in the form of Energy Performance Certificates (EPC) (AENOR, 2012; European Commission, 2010), which are aimed at showing the energy performance of buildings and informing end-users of potential energy savings (European Commission, 2015a). However, most EPC procedures are based on standard operating conditions, occupancy profiles, and other default values that generate discrepancies between energy simulation and real energy use (Lizana et al., 2017). The results of these standard procedures distort the EPC purpose of informing about the real energy saving potential (European Commission, 2015a), so one of the main challenges in energy renovation is how to obtain realistic energy saving values according to real energy consumption patterns.

Different studies have identified and discussed the high impact of energy-related occupant behaviour on the economic and energy performance of low-carbon retrofitting actions. Wallis et al. (2016) suggested that the use of energy behavioural attitudes provides more detailed information about the electricity consumption and thus allows choosing a more appropriate policy planning. According to Hong et al. (2016), occupant behaviour greatly influences the real consumption by using the thermostat settings, opening or closing windows, use of air conditioning systems, lights and stand-by of appliances, among others. Stieß and Dunkelberg 
(2013) developed an empirical study of 1000 homeowners in Germany which considers the importance of users' knowledge about energy consumption related to the decision-making process in standard refurbishment measures. Bedir and Kara (2017) studied the influence of consumption patterns on different profiles of electricity consumption in Dutch housing stock. Liang et al. (2016) proposed the need to design a decision-making system that considers the influence of the occupation model and the occupant behaviour to achieve a green retrofit. Li et al. (2018) identified the influence of different types of end-users in the final success of interventions, suggesting participatory decision/evaluation procedures that involve them in sustainable projects. Perera et al. (2018) stated that, including a socioeconomic evaluation is crucial, to identify the most desirable interventions in building renovation for different profiles, through a multi criteria decision-making approach. Serrano-Jiménez et al. (2017) introduced a new energy renovation strategy which proposed different levels of intervention (mild, moderate and intense), based on the socioeconomic context of each region, going against the European concept of deep renovation adopted by the Global Building Performance Network (GBPN, 2013), and evaluating interventions adapted to each requirement (Femenías et al., 2018).

As a step forward, this research defines a new economic and energy assessment method of energy efficiency measures to support decision-making in energy retrofitting of multi-family buildings. It involves a parametric analysis between different energy retrofit alternatives and energy consumption scenarios of dwellings (standard and real energy consumption profiles: high, medium and low), overcoming the problem that emerges when different users or stakeholders do not follow the consumption standards of EPC procedures. The method allows identifying best available solutions for all dwelling scenarios, guaranteeing the global profitability of actions, according to every energy-related occupant behaviour.

The novelty of this method is based on the integration of real scenarios based on energy-related occupant behaviour in energy simulations together with those operating parameters established by the EPC standards, to evaluate both the energy and economic savings of energy efficiency measures, through a sensitivity analysis. This procedure fulfils two main purposes of the EPBD and EPC [24]: showing the energy performance of the building to enable comparisons with other buildings; and, informing end-users of potential energy savings, in order to motivate them to invest in improving the energy efficiency of the building. It uses a model's iterative calibration procedure, based on real building performance, which allows a high final accuracy to be achieved. This method enables a new procedure that allows homeowners, landlords or investors to identify the most appropriate energy retrofitting actions in each scenario, as suggested by Bolis et al. (2017) or Pombo et al. (2016), showing real economic feasibility. In addition, the graphic output of the results allows sustainable strategies to be designed, according to the effectiveness and feasibility of solutions, for all energy-related behaviour contexts.

The paper is structured as follows. Firstly, the method is defined in a general scheme, where the main contributions are highlighted, and the five stages into which it is divided are defined. Secondly, the method is applied in a residential neighbourhood in Southern Europe, considered as a reference multi-family building typology, due to its construction period, constructive composition and low-medium income population. Thirdly, energy efficiency measures (EEMs) and packages are evaluated in different energy consumption scenarios, where the total investment cost (IC), the annual thermal energy demand (ED), the primary energy consumption (PEC), and the Net Present Value (NPV), are calculated and compared. Finally, the results are discussed, and the most appropriate measures or packages are identified, according to each scenario, as well as reporting strategies and guidelines to support the decision-making process for a sustainable low-carbon energy retrofitting. 


\section{MATERIALS AND METHOD}

127 Figure 1 defines the assessment method to evaluate the energy savings and economic 128 reinvestments of energy retrofit projects in residential buildings. The method is designed to be applied and adapted to any residential neighbourhood by previously requiring real energy data, per dwelling, to identify the different energy consumption patterns of their occupants.

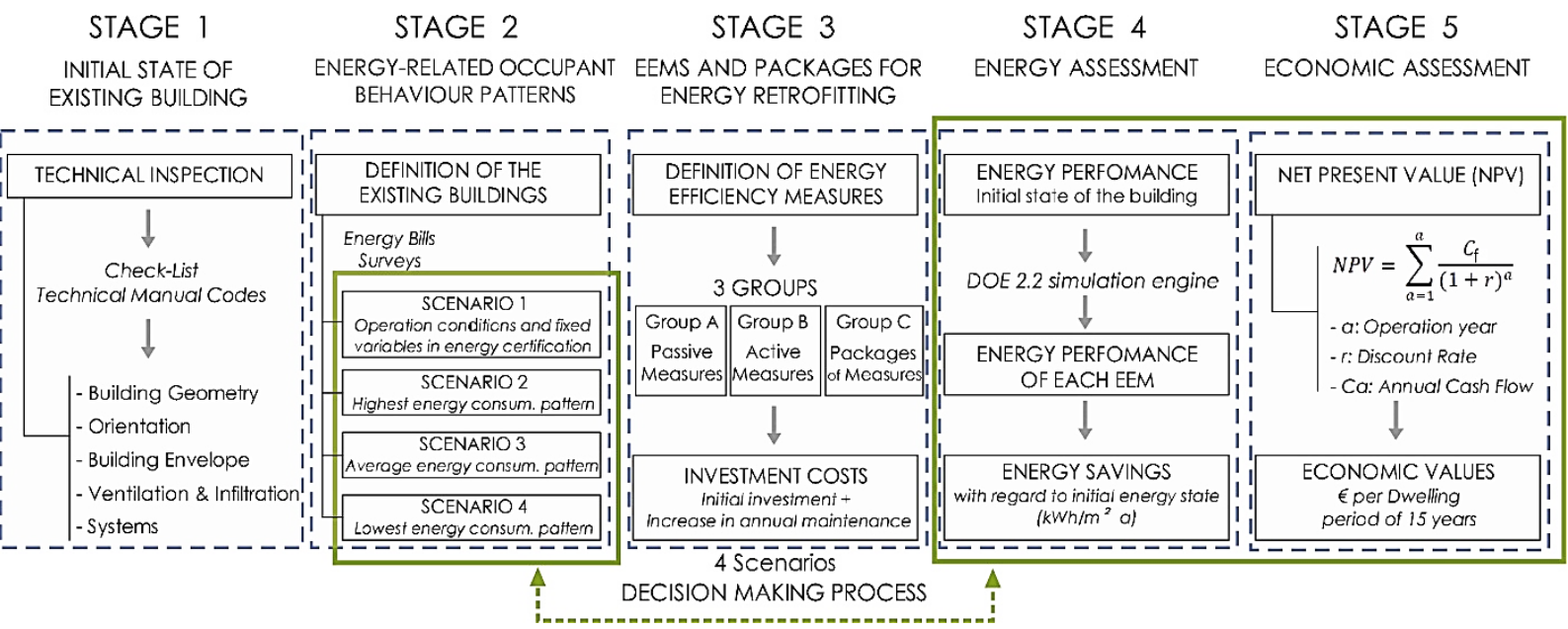

Figure 1. Five-stage operation of the decision-support assessment method.

134

135

136

137

138

139

140

141

142

143

144

145

146

147

148

149

150

151

152

153

154

155

156

157

158

159 。

160

161

162

163

As a step beyond the previous studies reported in the introduction, this research involves extra variables by carrying out a parametric analysis with four consumption scenarios, three of them according to real data from the occupants, and one of them, following the standard parameters of EPC procedures. This research extends the results obtained in previous studies where the return on investment, in different cost-optimal measures, are compared with one energy consumption pattern, such as in Tadeu et al. (2016), Lizana et al. (2016), or Serrano-Jiménez et al. (2017). This concept promotes decision-making in energy retrofitting through a joint assessment of different energy consumption patterns. Stages 4 and 5 are in continuous relation with Stage 2, which generates a more complete sensitivity analysis and helps the investor to identify which proposals would be the most appropriate for each case study. In addition, the inclusion of Stage 3, which is organised into three groups of passive, active and packages of actions, allows useful results to be obtained for the small investor on the performance of individual actions, and offers an overall analysis of the wide range of possibilities that induces energy retrofitting in different proposals or packages (Ascione et al., 2015). The five stages, into which this method is structured, are defined in detail below.

- Stage 1. Initial state of the existing building. The diagnosis of the initial state of the building is obtained through technical inspections and energy audits following different normalised procedures (AENOR, 2015; Gobierno de España, 2013a, 2013b) and specific technical manuals and codes (Ministerio de Fomento, 2013; Ministerio de Vivienda, 2006). Building geometry, location, orientation, constructive composition of the building envelope (façades, roofs, floors and windows), ventilation and infiltration rates, as well as heating, cooling and hot water systems, are characterised.

- Stage 2. Energy-related occupant behaviour patterns. The operating conditions and energy consumption patterns in each dwelling are evaluated for the energy simulation, through occupant surveys and energy bill assessments. Hourly operating schedules of occupation (weekday and weekend), operating profiles of systems, lighting for internal gains, and set-point temperatures, are specifically defined for each energy-related scenario. Four scenarios are 
considered for the sensitivity analysis. Scenario 1 is characterised by the operating conditions and default values of local EPC procedures. Scenarios 2, 3 and 4 represent the low, medium and high consumption profiles for the case study, which are calibrated according to real energy consumption data (energy bills), through an iterative calibration process. Further details of the scenarios are described below:

-Scenario 1 is defined by the operating conditions and fixed parameters used for the EPC in the region (European Commission, 2010; Gobierno de España, 2013b; Ministerio de Vivienda, 2009). Set-point temperatures for on-peak and off-peak occupancy periods are fixed at $25^{\circ} \mathrm{C}$ and $27^{\circ} \mathrm{C}$ for cooling, respectively, and $20^{\circ} \mathrm{C}$ and $17^{\circ} \mathrm{C}$ for heating. The internal gains generated by occupants, lighting and appliances are considered according to specific schedules.

- Scenario 2 considers the highest energy consumption pattern among all dwellings, according to the results obtained in surveys and energy bills. Operating conditions are based on survey results and calibrated according to energy bill data.

- Scenario 3 is characterised by the medium energy consumption pattern of all dwellings according to the results obtained in surveys and energy bills. Operating conditions are based on surveys and calibrated according to the performance, which is determined through the average of the energy bill data.

- Scenario 4 considers the lowest energy consumption pattern among all dwellings according to the results obtained in surveys and energy bills. Operating conditions are based on surveys and calibrated according to energy bill data.

186 Stage 3. EEMs and packages for energy retrofitting. A portfolio of individual technical EEMs and packages to reduce thermal energy demand and consumption are defined and characterised. Aiming to facilitate the comparison between the results, solutions are organised into three groups: individual passive measures (group A); individual active measures (group B); and, packages of measures (group C). The investment cost (IC) and the increased maintenance costs are defined for each EEM. Data are obtained from local databases and manufacturers' reports.

194 - Stage 4. Energy assessment. The current energy performance of the building is evaluated by the DOE 2.2 simulation engine. Then, the implementation of the proposed EEMs and packages are simulated in each energy consumption scenario. The initial energy models for each scenario are calibrated considering the different energy consumption profiles, which were characterised in Stage 2.

200 - Stage 5. Economic assessment. The economic reinvestment of EEMs for each energy economic concept for analysing the profitability of a planned investment or project. This term is calculated within this research for each energy efficiency measure or package, and offers the difference between the present value of cash inflows, and the present value of cash outflows over a period of time. NPV is evaluated according to Eq. 1, where $a$ is the operation year, $r$ the discount rate, and $C_{f}$ the annual cash flow.

$$
N P V=\sum_{a=1}^{a} \frac{C_{f}}{(1+r)^{a}}
$$


operation year is set at 15 years, due to the high percentage of aging population and the socioeconomic level being low-medium, which demands a short-term amortization period (Kovacic et al., 2015). After 15 years, most of the elderly will be over 80 years old, which is nearly the average national life expectancy (Instituto Nacional de Estadística, 2013; Serrano-Jiménez et al., 2018).

The discount rate $(r)$ is the rate of return used in a discounted cash flow analysis to determine the present value of future cash flows. This is an important value that should be decided for each context, according to the economic situation. Figure 2 shows the discount rate values of low-risk banking products from the National Bank of Spain (Banco de España, 2017), during recent years. Although there has been a significant drop in the trend, due to the financial crisis, the end of the quantitative easing has meant that new economic expectations for the European context estimate an increase of these rates, in a range of between 3 and $6 \%$, for the coming years (Hermelink et al., 2016; Mata et al., 2015). Therefore, $4.5 \%$ has been fixed as a discount rate that is adapted to these new expectations, in addition to taking into account this application context with reduced investments, and a moderate investor profile.

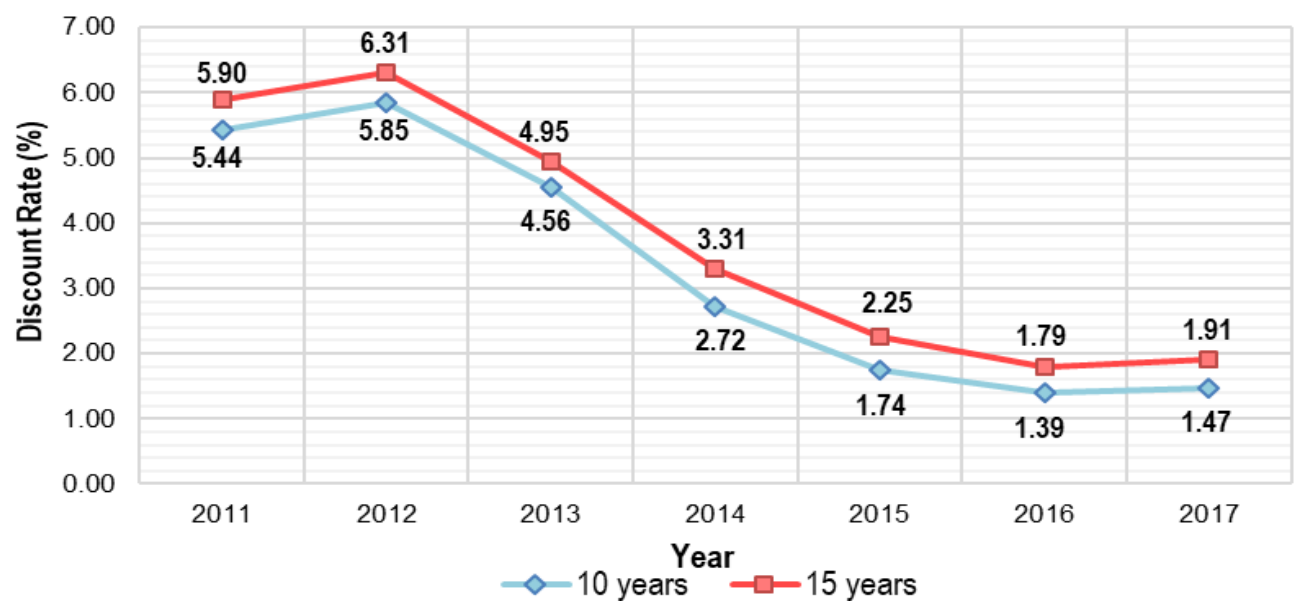

Figure 2. Evolution of the discount ratio values during the last years.

Lastly, $C_{f}$ is calculated as a function of the initial IC $(€)$ and the annual economic savings per costs. In fact, annual operating costs $(€)$ include an annual energy price increase of $4.5 \%$, according to its evolution over recent years (IDAE, 2015a, 2015b), and the different expected scenarios for each energy source (IDAE, 2011; Prasanna et al., 2018). These values also need to be adapted to each region and socioeconomic context.

\section{REFERENCE CASE STUDY}

A residential set of multi-family buildings known as "Remedios Viejo", and located in Seville (Spain), was selected as the case study (Figure 3). It was built in 1942 and represents a reference building sample of the mid-twentieth century in Mediterranean cities that currently has several energy renovation needs (Barrios-Padura et al., 2015; Gamarra et al., 2018). This case study pertains to the large housing stock of European cities, with more than a third of multi-family buildings, prior to 1970 (European Commission, 2015b). Moreover, it presents an aging population with $32 \%$ of its inhabitants over 65 years of age, representative of the world population aging trend.

The neighbourhood has 324 dwellings that are divided into nine closed blocks. Each block consists of four multi-family residential buildings of three storeys in height, enclosing a private 
inner courtyard. All the dwellings have the same size, and occupancy ranges between one and four residents per dwelling, with an average occupation value of 2.61 (IECA, 2012).

The residents of these buildings participated in this research, by responding to a brief survey about the operating conditions and occupation periods in their dwellings, as well as to questions related to behavioural patterns in energy consumption. The occupants also provided energy bills with real energy consumption values from recent months. The participation sample was collected from 176 dwellings, which represents $54 \%$ of the apartments in the neighbourhood.

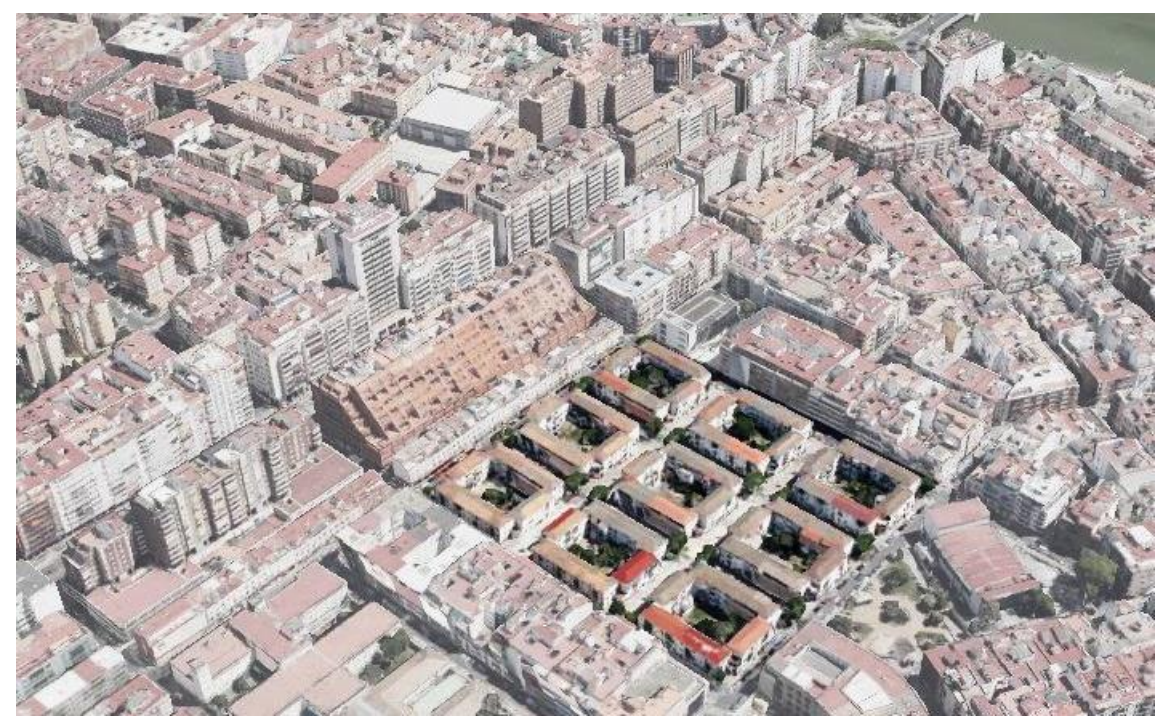

Figure 3. Aerial location of the case study.

The case study was also characterised through technical inspections and audits. Main characterisation parameters for the energy simulation are summarised in Table 1. Data are divided into two groups: building envelopes and systems.

Table 1. Building characterisation for the energy assessment. Main parameters.

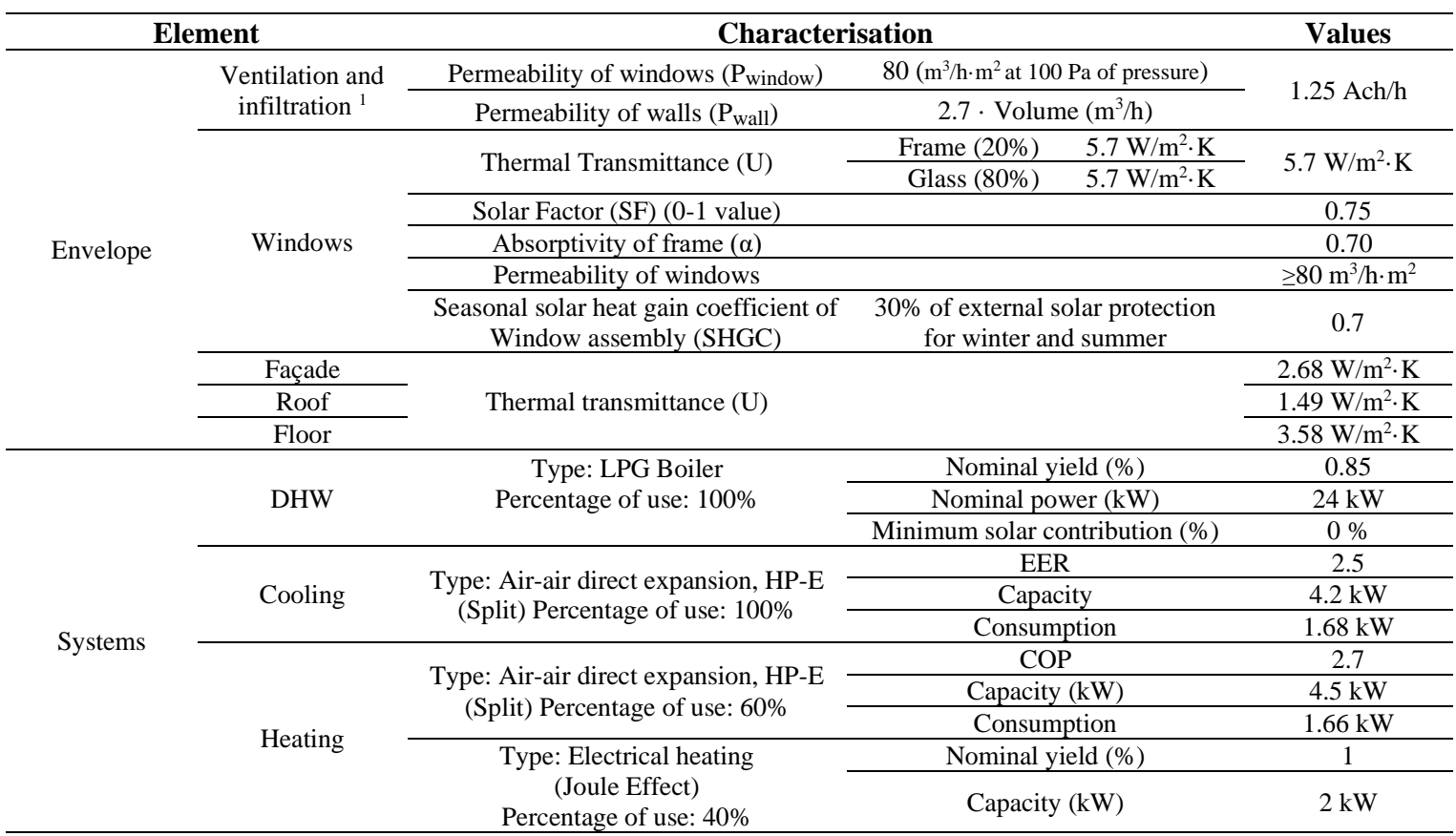


The building typology has a poor energy performance, with no insulation and low-quality materials. The façades present a deteriorated conservation status. Windows are characterised by a simple glazing and high infiltrations. Most of the heating and cooling conditioning systems are newly incorporated with mono-split, and/or, electric heating (electric radiators).

\section{Domestic hot water is usually obtained through a gas
3.1. Economic and energy consumption patterns}

The economic and energy consumption scenarios considered for sensitivity are defined in Figure 4 and Table 2. Figure 4 illustrates the primary energy consumption (PEC) values $\left(\mathrm{kWh} / \mathrm{m}^{2} \mathrm{a}\right)$, relative to DHW, heating and cooling and other consumption sectors, in each scenario. These PEC values were obtained as a function of final energy consumption results taken from energy audits, and PEC conversion factors of used energy sources, for the specific region under assessment. Associated annual energy bills, per scenario, are shown in Table 2.

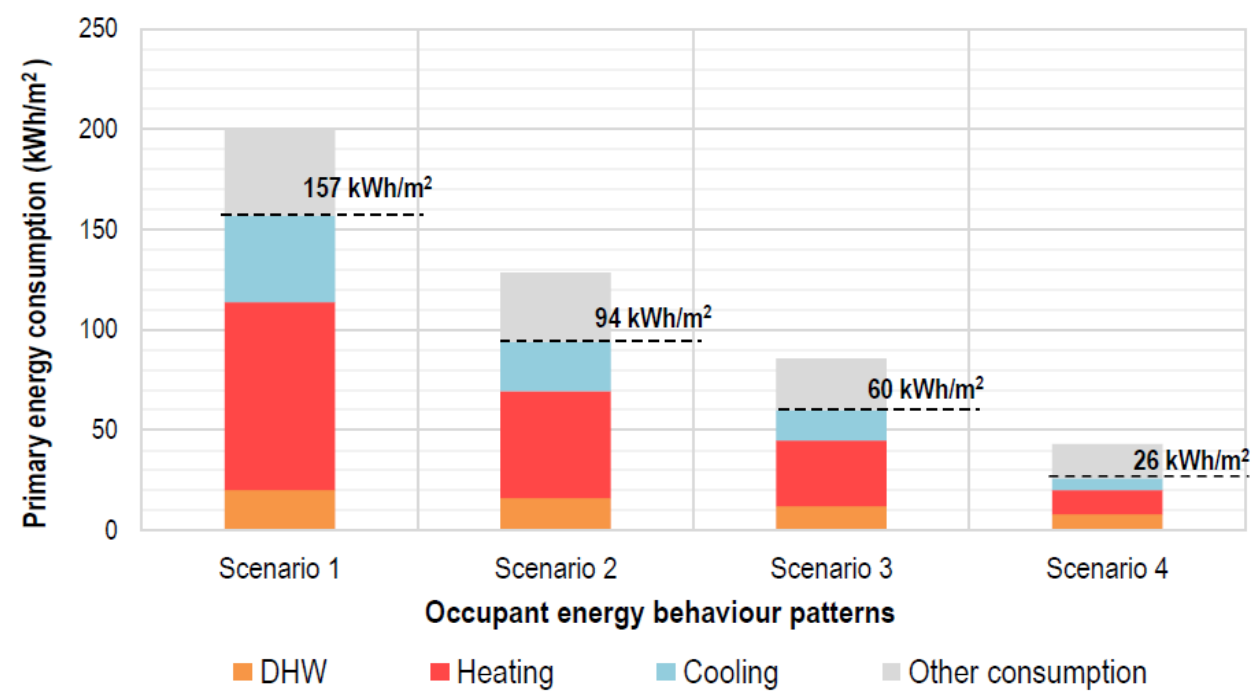

Figure 4. Occupant energy behaviour patterns evaluated in the case study.

Table 2. Annual energy bill per dwelling with occupant behaviour patterns.

\begin{tabular}{ccccc}
\hline & Scenario 1 & Scenario 2 & Scenario 3 & Scenario 4 \\
\hline Annual PEC $\left(\mathrm{kWh} / \mathrm{m}^{2}\right)^{\mathrm{a}}$ & 199.91 & 128.47 & 85.75 & 43.04 \\
\hline Annual energy bill $(€)^{\mathrm{b}}$ & $2,445.86$ & $1,651.94$ & $1,182.72$ & 713.50 \\
\hline $\begin{array}{l}\text { a. Including energy consumption of DHW, Heating, Cooling and other consumption sectors. } \\
\text { b. Not including national taxes. }\end{array}$ & & & \\
\hline
\end{tabular}

- Scenario 1 corresponds to the energy consumption pattern according to fixed values considered for national EPC procedures, representing an annual energy cost of 2,445.86€ per dwelling, which is not adjusted to reality. This is due to the fact that default values for energy simulation engines generate discrepancies with regard to real energy use, resulting in seemingly distorted consumption.

- Scenario 2, which represents the highest value from the energy bills in all the dwellings, is characterised by $1,651.94 €$ per year per dwelling.

- Scenario 3, which identifies the average value of the energy consumption in all dwellings, consists of an annual energy bill of 1,182.72€ per dwelling.

- Scenario 4, which represents the lowest value from the energy bills in all dwellings, is characterised by $713.50 €$ per year per dwelling. 
It is essential to highlight that the medium scenario (Scenario 3) supposes $42-48 \%$ of the economic and energy results, for the prefixed standard profile for EPC procedures (Scenario 1). Thus, although the official certification allows evaluation and comparison of energy performance in different existing buildings, it is shown that it uses excessive consumption profiles, with respect to the real values evidenced in energy bills.

Considering these scenarios, four energy simulation models, one per scenario, were carried out through the DOE 2.2 simulation engine, by means of an iterative calibration procedure. Once each building model was characterised, those uncertain operating conditions were adjusted to calibrate the energy model, according to real energy bill values reported in each scenario.

\subsection{Energy efficiency measures. Criteria and proposals}

Table 3 shows the set of individual measures and packages of energy efficiency interventions selected for improving the energy performance of the residential building. For each group, initial investment cost, increase in annual maintenance cost, and main characterisation parameters, are defined. Three groups of EEMs are presented: group A consists of passive measures; group B consists of active measures to upgrade heating, cooling and hot water systems; and, group C consists of packages of measures combining specific solutions of group A and B. The defined measures cover a wide variety of possibilities in energy renovation in residential buildings, with actions that involve modifying the building envelope (a1-a3), improving thermal performance in windows (a4-a5), adding insulation (a6-a8), or improving the system performance, with different energy sources and operating conditions. The organisation of these three groups allows easy comparison of the performance of passive, active and packages of measures in the four consumption scenarios.

Table 3. Definition and economic characterisation of proposed EEMs.

\begin{tabular}{|c|c|c|}
\hline Definition of measures and packages & $\begin{array}{c}\text { Investment } \\
\text { cost per } \\
\text { building }(€) \\
\end{array}$ & $\begin{array}{c}\text { Investment } \\
\text { cost per } \\
\text { dwelling }(€) \\
\end{array}$ \\
\hline \multicolumn{3}{|l|}{ Group A. Passive measures } \\
\hline $\begin{array}{l}\text { a1. Sealing of frames in windows (Improvement of airtightness). } \\
(1.17 \mathrm{ach} / \mathrm{h})\end{array}$ & $1,725.92$ & 143.83 \\
\hline $\begin{array}{l}\text { a2. Rollable awnings in the façade (Rigid slats). } \\
\text { (SHGC: Summer }=0.2 ; \text { Winter }=0.7 \text { ) }\end{array}$ & $16,424.30$ & $1,368.69$ \\
\hline $\begin{array}{l}\text { a3. Hanging awnings in the façade (Textile). } \\
\text { (SHGC: Summer }=0.4 \text {; Winter }=0.7 \text { ) }\end{array}$ & $18,566.60$ & $1,547.22$ \\
\hline $\begin{array}{l}\text { a4. Double windows (adding a new window with double glazing to the previous one). } \\
\left(0.97 \mathrm{ach} / \mathrm{h}, \leq 27 \mathrm{~m}^{3} / \mathrm{h} \mathrm{m}^{2} ; \text { Uwindow correct factor=0.37) }\right.\end{array}$ & $33,235.40$ & $2,769.62$ \\
\hline $\begin{array}{l}\text { a5. New windows (aluminium frames thermal break TB and double glazing). } \\
\left(0.90 \mathrm{ach} / \mathrm{h}, \leq 9 \mathrm{~m}^{3} / \mathrm{h} \mathrm{m} \mathrm{m}^{2} ; \text { Uwindow }=2.3 \mathrm{~W} / \mathrm{m}^{2} \cdot \mathrm{K} ; \alpha=0.30\right)\end{array}$ & $42,299.60$ & $3,524.97$ \\
\hline $\begin{array}{l}\text { a6. Exterior insulation in the façade EIFS (Expanded polystyrene }- \text { EPS }) \text {. } \\
\left(0.90 \mathrm{ach} / \mathrm{h} ; \text { Ufaçade }=0.57 \mathrm{~W} / \mathrm{m}^{2} \cdot \mathrm{K}\right)\end{array}$ & $37,415.00$ & $3,117.92$ \\
\hline $\begin{array}{l}\text { a7. Exterior insulation in the façade EIFS }(\text { Cork }) \text {. } \\
\left(0.90 \mathrm{ach} / \mathrm{h} ; \text { Ufaçade }=0.61 \mathrm{~W} / \mathrm{m}^{2} \cdot \mathrm{K}\right)\end{array}$ & $41,904.80$ & $3,492.07$ \\
\hline $\begin{array}{l}\text { a8. Interior insulation in the roof by interior cladding (Extruded Polystyrene - XPS) } \\
\left(1.15 \mathrm{ach} / \mathrm{h} ; \text { Uroof }=0.37 \mathrm{~W} / \mathrm{m}^{2} \cdot \mathrm{K}\right)\end{array}$ & $12,334.80$ & $1,027.90$ \\
\hline \multicolumn{3}{|l|}{ Group B. Active measures } \\
\hline $\begin{array}{l}\text { b1. Reversible heat pump (Heating and cooling). } \\
\text { (EER=4.2; Cap: 4.2kW; Cons:1.00kW- COP: 4.6; Cap:4.5kW; Cons: } 4.5 \mathrm{~kW})\end{array}$ & $20,400.00$ & $1,700.00$ \\
\hline $\begin{array}{l}\text { b2. Aerothermal heat pump (Heating, cooling and DHW). } \\
\text { (EER=3.8; Cap: 7.1kW; Cons:1.9kW - COP: 3.6; Cap:8 kW; Cons: 2.3kW) }\end{array}$ & $81,600.00$ & $6,800.00$ \\
\hline $\begin{array}{l}\text { b3. Solar thermal energy }(\mathrm{DHW}) \\
\text { (Minimum Solar Contribution: } 70 \%)\end{array}$ & $17,304.00$ & $1,442.00$ \\
\hline $\begin{array}{l}\text { b4. Photovoltaic energy support system (Heating, cooling and } D H W \text { ). } \\
\text { (Contribution: } 2,050 \mathrm{kWh} ; 14 \mathrm{~m}^{2} \text { panels; Forecast gen. } 2.78 \mathrm{kWh} / \mathrm{year} \text { ) }\end{array}$ & $12,320.00$ & $1,026.67$ \\
\hline $\begin{array}{l}\text { b5. Centralised biomass boiler (Heating and } D H W \text { ). } \\
\text { (Nom. Yield: } 78 \% \text {; Nom. Power: } 130 \mathrm{~kW} \text { - Num. radiator: 4; Power:1.6kW) }\end{array}$ & $35,000.00$ & $2,916.67$ \\
\hline $\begin{array}{l}\text { b6. Individual biomass boiler (Heating). } \\
\text { (Nom. Yield: } 91 \% \text {; Nom. Power: } 5 \mathrm{~kW} \text { ) }\end{array}$ & $19,320.00$ & $1,610.00$ \\
\hline
\end{tabular}


b7. Centralised condensing boiler (Heating and $D H W$ ).

(Nom. Yield: 93\%; Nom. Power: 170kW - Num. radiator: 4; Power:1.6kW)

$16,420.00 \quad 1,368.33$

b8. Micro-cogeneration (Heating and $\mathrm{DHW}$ ).

(Nom. Yield: $81 \%$; Nom. Power: 30.5kW - Num. radiator: 4; Power: 1.6kW)

$55,420.00 \quad 4,618.33$

Group C. Packages of measures

c1. Rollable awnings + New windows.

$(\mathrm{a} 2+\mathrm{a} 5)$

c2. Rollable awnings + New windows + Façade insulation.

$(\mathrm{a} 2+\mathrm{a} 5+\mathrm{a} 6)$

c3. New windows + Façade and roof insulation.

$(\mathrm{a} 5+\mathrm{a} 6+\mathrm{a} 8)$

c4. Rollable awnings + New windows + Façade and roof insulation.

$(\mathrm{a} 2+\mathrm{a} 5+\mathrm{a} 6+\mathrm{a} 8)$

c5. Rollable awnings + New windows + Solar thermal energy.

$(\mathrm{a} 2+\mathrm{a} 5+\mathrm{b} 3)$

c6. New windows + Reversible heat pump.

$(\mathrm{a} 5+\mathrm{b} 1)$

c7. New windows + Reversible heat pump + Solar thermal energy.

$(\mathrm{a} 5+\mathrm{b} 1+\mathrm{b} 3)$

c8. New windows + Aerothermal heat pump.

$(\mathrm{a} 5+\mathrm{b} 2)$

c9. Rollable awnings + New windows + Façade and roof insulation + Solar thermal energy.

$(\mathrm{a} 2+\mathrm{a} 5+\mathrm{a} 6+\mathrm{a} 8+\mathrm{b} 3)$

a All costs incurred up to the point when the building or the dwelling element is delivered to the customer, ready to use. These costs include design, purchase of building elements, connection to suppliers and installation, and commissioning processes, not including national taxes.

321

322

323

324

325

326

327

This method necessarily involves evaluating the energy and economic performance of packages of measures, since it is very common to combine them in building renovation proposals. The criteria for grouping the packages have mainly considered technical, constructive and economic factors that promote a significant reduction of the energy use. The packages are formed by passive measures with a high potential to reduce energy demand (c1-c4), as well as including those active measures with better energy performance (c5-c9).

\section{RESULTS AND DISCUSSION}

The results of this decision-support method are presented for each group of measures in two different sections. First, the results relate the investment cost and the reduction of thermal energy demand of each measure or package, and second, the sensitivity analysis relates the energy savings and the NPV values, according to the four defined consumption scenarios.

\subsection{Analysis between investment cost and annual energy demand of EEMs}

Figures 5 and 6 illustrate the relationship between investment costs and the annual thermal energy demand, per dwelling $\left(\mathrm{kWh} / \mathrm{m}^{2} \mathrm{a}\right)$, of the building in its initial situation and in scenarios considering the implementation of selected energy efficiency measures. Illustrated annual thermal energy demand is associated with heating, cooling and DHW, according to the occupancy and operating conditions defined for Scenario 1, which represents the standard operating conditions corresponding to the Spanish EPC procedure. This figure allows the measures with the highest potential to improve indoor thermal comfort, with respect to the investment costs, to be identified. The aim of this analysis is to highlight EEMs with the lowest investment cost per dwelling (IC, $€$ ), and lowest annual energy demand (ED, $\mathrm{kWh} / \mathrm{m}^{2} \mathrm{a}$ ), with respect to the initial state. 

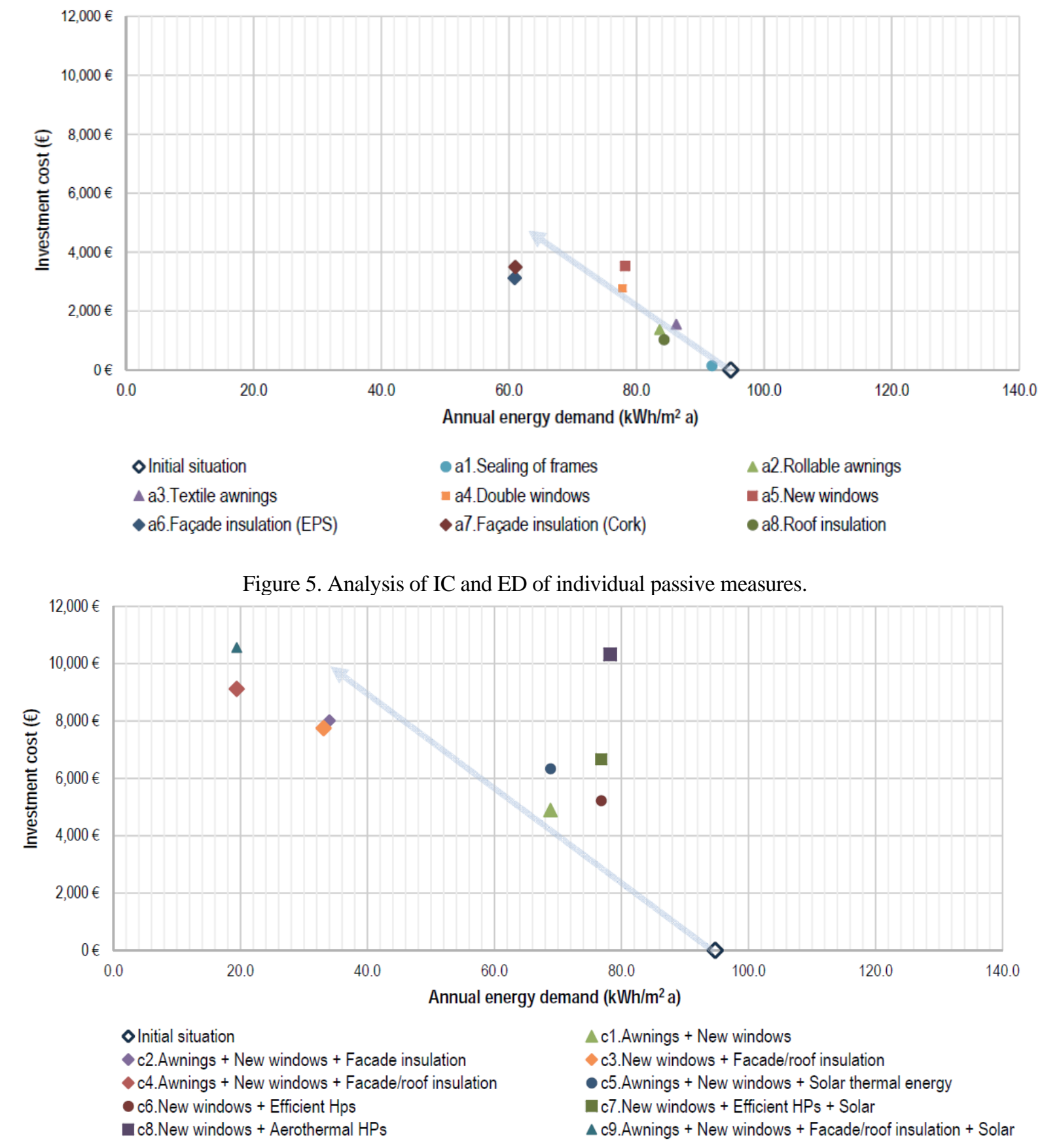

Figure 6. Analysis of IC and ED of packages of measures.

Following Figure 5, the most favourable passive measures are a6 and a7, both related to the incorporation of insulation in the façade of the building. These measures lead to a reduction of the annual energy demand of $35 \%$, with an investment cost lower than 4,000€ per dwelling. The group B of active measures was not illustrated as they do not show reduction in energy demand. Finally, according to Figure 6, the most favourable package is $\mathrm{c} 4$, which includes only passive measures: awnings + new windows + façade/roof insulation. This package introduces a very significant reduction in energy demand, of almost $80 \%$, with respect to its initial state, and an investment cost of less than $10,000 €$ per dwelling. 
This preliminary analysis of the results under Scenario 1 allows a comparison of the performance of these measures with other scenarios in the following section, under a sensitivity analysis, considering users' consumption scenarios.

\subsection{Sensitivity analysis between NPV and annual PEC}

Figures 7, 8 and 9 show the NPV and annual PEC (considering heating, cooling and DHW) performance of each EEM, through a sensitivity analysis for different energy-related occupant behaviour scenarios. The aim is to highlight the EEMs with the highest NPV, per dwelling $(€)$, and the lowest annual PEC $\left(\mathrm{kWh} / \mathrm{m}^{2}\right.$ a). These figures allow the identification of the measures with the best potential to reduce energy consumption, with highest economic reinvestment, and lowest investment risk.

Each EEM is represented by a symbol and located, according to its NPV value and its PEC value, in the four defined scenarios. Each dotted line links the performance of the same measure in Scenarios 1-4. In addition, a semi-transparent trend line with arrow appears for highlighting the trend line of the group of measures in each scenario. The initial energy state of the building in each scenario is represented with an open diamond, so the energy savings would be evaluated with respect to the starting point of each scenario. Finally, those values of NPV that exceed $0 €$, in the NPV axis, indicate a trend to a positive reinvestment of the global cost over the period of 15 years.

Figure 7 summarises the energy and economic performance of passive measures (group A) for all energy consumption scenarios.

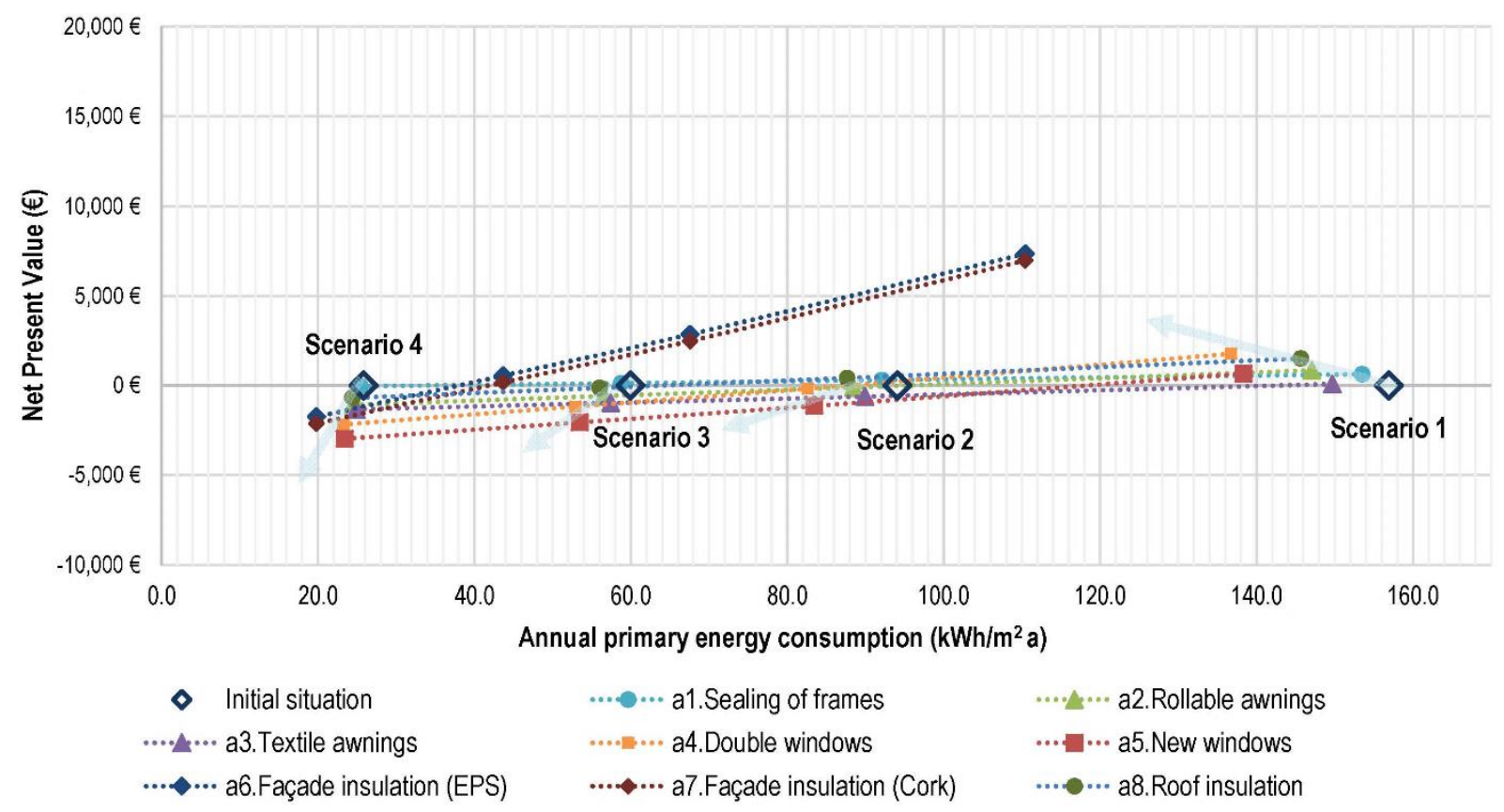

Figure 7. Sensitivity analysis between NPV and PEC of passive measures.

The trend line of passive measures varies according to each scenario. It is observed that the percentage reduction of energy consumption, with respect to the initial state, is almost constant in the four scenarios, being situated between $2 \%$ and $20 \%$ from the initial state. The performance of the measures a6 and a7 particularly shows a great reduction of energy consumption in all scenarios. However, NPV values are variable according to each scenario. The impact of the consumption patterns on the PEC-NPV relationship, in passive measures, 
reaches variations of up to $10,000 €$ and $90 \mathrm{kWh} / \mathrm{m}^{2}$ a between different scenarios. Scenario 3 shows reduced NPV economic reinvestment values, and in Scenario 4 most of them are unfavourable, having negative NPV values. In addition, the dotted lines that link the performance of some measurements are practically horizontal, which indicates that the NPV value has low economic risk of implementation.

Figure 8 shows the energy and economic performance of active measures to upgrade heating, cooling and hot water systems (group B) for all energy consumption scenarios.

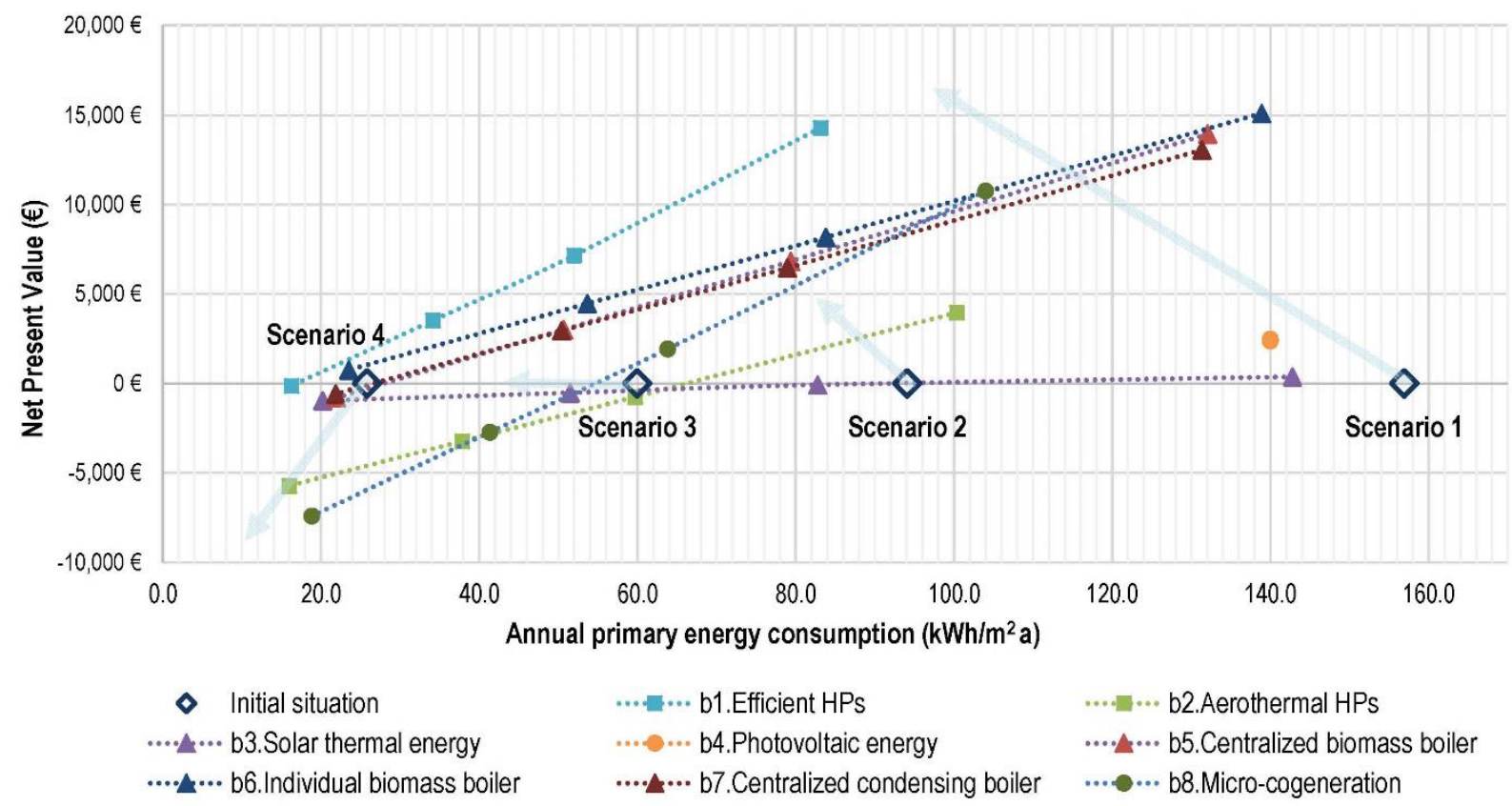

Figure 8. Sensitivity analysis between the NPV and PEC of active measures.

The energy and economic performance is much more variable than in the passive solutions. Moreover, regarding PEC values, unlike passive measures, the percentage of energy consumption reduction varies, according to each scenario. In addition, the impact of users' consumption scenarios on active measures offers highly different values to those previously analysed, reaching NPV variation values for the same energy efficiency measure of up to $17,000 €$, and an energy reduction of $140 \mathrm{kWh} / \mathrm{m}^{2} \mathrm{a}$, between Scenario 1 and 4 .

Active measures introduce consumption reduction values up to $45 \%$, highlighting measure b1. Regarding NPV values, most measures have a positive economic reinvestment, in many cases surpassing a 5,000€ benefit. In addition, the dotted lines that join measures are much steeper, which indicate significant changes in NPV values, according to the considered scenario. In analysing each measure, measures b1 and b2 introduce percentages of energy reduction of more than $30 \%$ in all scenarios, although the percentage may be variable, according to the consumption pattern. Exceptionally, measures b1 and b6 have positive NPV values in all scenarios. 
Figure 9 illustrates the energy and economic performance of packages of measures combining specific solutions regarding groups A and B (group C) for all the energy consumption scenarios.

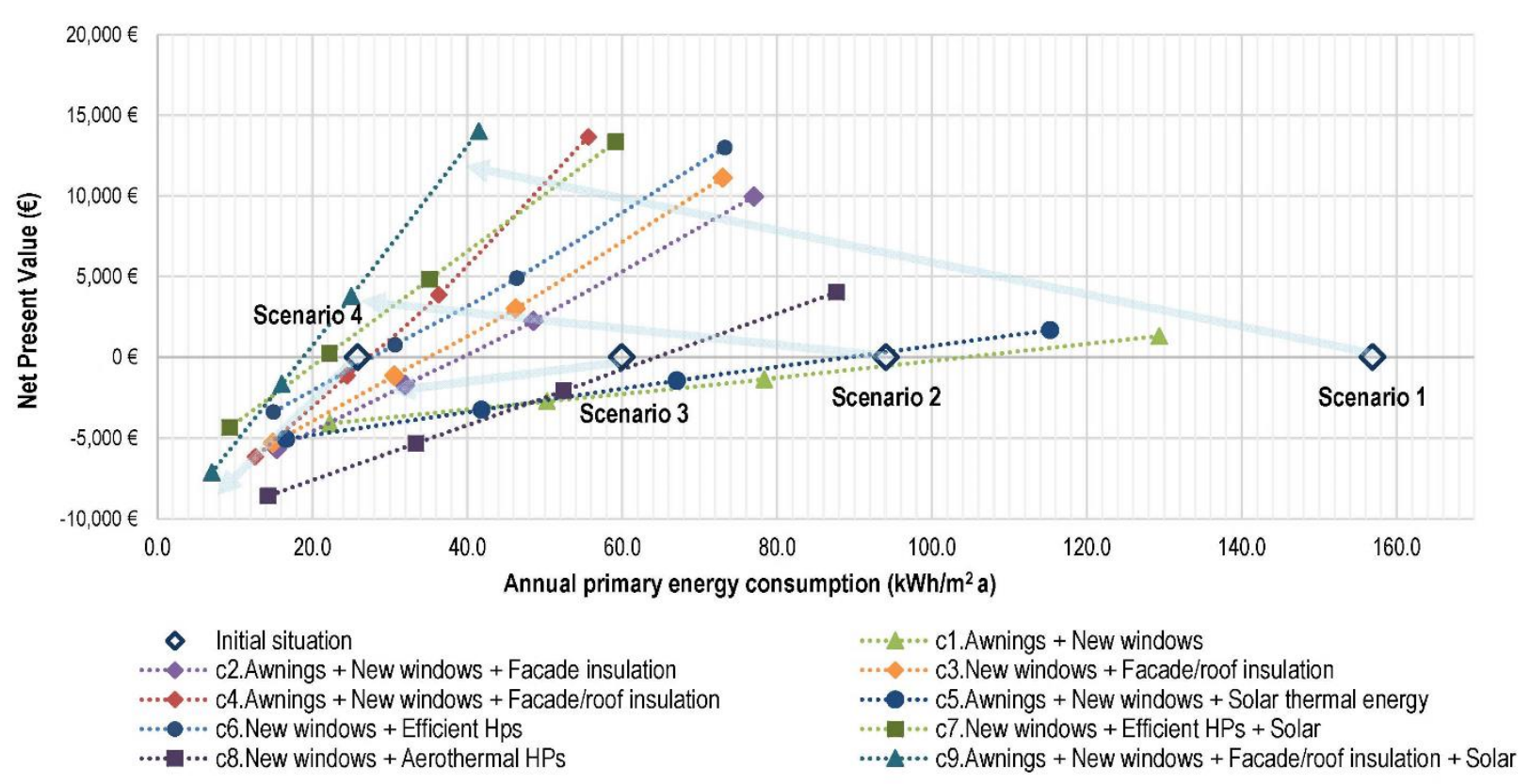

Figure 9. Sensitivity analysis between NPV and PEC of packages.

The impact of energy consumption patterns on PEC and NPV is highly significant. There are some packages that reach an $80 \%$ energy saving. Regarding the NPV values, there are very high variations between one scenario and another. The same package can have enormous gains for one scenario, or huge losses for another, with variations of up to $20,000 €$.

For Scenario 1 and 2, the profitability of solutions is mostly positive, however for Scenarios 3 and 4, most of the values are negative. In addition, the dotted lines that join each package are very steep, which supposes a great variation between one consumption pattern and another. Comparing every package, although c 9 has the best energy performance, the NPV reinvestment values can be favourable or unfavourable, according to each scenario. In fact, no package of measures has favourable NPV values in Scenario 4, so the economic effectiveness of these actions is only obtained with medium or high consumption patterns.

Comparing the reported results, a high variation in economic and energy performance of energy retrofitting measures is found per energy consumption scenario. These new findings highlight the importance of adjusting decision-making models in energy retrofitting to real energy consumption patterns, and not only taking into account standard operating conditions, to fulfil two main purposes of the EPBD and EPC procedures: enabling comparisons with other buildings, and informing end-users of potential energy savings. All these advances justify the significance of this study, promoting profitable and efficient energy renovation proposals adjusted to the socioeconomic context of each neighbourhood.

Lastly, other particular contribution of this method is the graphic output of the obtained results, which summaries the sensitivity analysis of solutions, comparing energy performance and the economic return on investment per scenario. It allows technicians, property owners, end-users and other stakeholders an easy check of different measures through an understandable graph, in which horizontal and vertical slopes highlight the economic affordability of solutions. It also 
facilities the decision-making in an early design stage of energy retrofitting interventions, and promotes a responsible and optimized building renovation.

456

457

458

459

460

461

462

463

464

465

466

467

468

469

470

471

472

473

474

475

476

477

478

479

480

481

482

483

484

485

486

487

488

489

490

491

492

493

494

495

496

497

498

499

500

501

\section{CONCLUSIONS}

This research develops a new procedure to support the decision-making process towards a sustainable energy retrofitting in the multi-family building stock. Different energy efficiency measures and packages are evaluated, through a parametric analysis in a reference multi-family building in Spain. The novelty of this method is based on the combination of energy and economic assessment of solutions in four different energy consumption scenarios, one from standard operating conditions from the national Energy Performance Certificate (EPC) procedure, and the others, from real energy consumption patterns (high, medium and low). This procedure fulfils two main purposes of the EPBD and EPC procedures, showing the energy performance of the building to enable comparisons with other buildings and informing end-users of potential energy savings, in order to motivate them to invest in improving the energy efficiency of the building. This method addresses new strategies for policy making processes by promoting energy renovation strategies through a profitability analysis based on real energy consumption data, and highlighting most appropriate energy efficiency measures according to real needs, leading to sustainable and profitable energy retrofitting actions.

The results obtained show that significant variations can be achieved between the different scenarios per dwelling, reaching, for the same energy efficiency measure, from 20 to $80 \%$ energy savings, and up to $20,000 €$ of variation in NPV values, according to the occupant behaviour scenario. Thus, to reach a high level of cost effectiveness, each intervention must be fully analysed according to each energy consumption pattern.

Considering NPV values, there are actions that have a positive or negative economic performance, according to the scenario in which they are analysed. It is also important to stress the importance of previously establishing the discount rate, as it is a highly influential factor in the economic context in which the study is located. The lines linking the economic performance of each measure, in different scenarios, vary considerably depending on whether they are active, passive or packages of measures. Horizontal slopes in graphics ensure a major investment security for the users, whereas higher slopes lead to large profits or losses, in the long-term, according to the consumption patterns.

Regarding the performance of energy efficiency measures, passive measures are the best energy efficiency actions for low-energy consumption patterns. Some active measures might be included in medium-energy consumption levels, while in high-energy consumption levels, it would be highly beneficial to include active energy efficiency measures, or packages, as they are likely to produce high reduction in energy consumption and very high economic reinvestment, according to the NPV results. There are active measures, such as b1 (efficient heat pump), and b6 (individual biomass boiler), that have a beneficial NPV assessment in the four scenarios, so their implementation would be economically viable in all the consumption patterns of this case study. Otherwise, passive measures, beyond regulating interior thermal comfort, introduce substantial reduction of the percentages of energy consumption with low investment risk, according to the most unfavourable scenario.

Finally, it is highlighted that fixed operating conditions in EPC procedures are excessive when compared with real consumption data, which implies imbalances in the results offered by official procedures for retrofitting criteria. This important finding represents a political challenge to 
overcome by official procedures, being a possible starting point for future research, towards more realistic procedures of energy and economic assessment for energy retrofitting solutions.

\section{ACKNOWLEDGEMENTS}

This work was supported as part of the European Regional Development Fund (ERDF) of the European Union for financial support through the project "(Re)habitation $+(\mathrm{Re})$ generation + (Re)programming. The recycling and sustainable management of Andalusian building stock. Management of habitable surroundings from criteria of active aging, gender and urban habitability", and also as part of the ClimACT Project (SOE1/P3/P0429EU), within the Interreg Sudoe Programme. The authors gratefully acknowledge the financial support of the Spanish Ministry of Education and Research through two, pre-doctoral contracts, granted to Francisco Jesús Lizana Moral (FPU14/06583) and Antonio José Serrano Jimenez (FPU15/00070). This research was also made possible due to the support of the "Institute of Architecture and Building Science" IUACC from the University of Seville (V-IUACC grants, mode B, 2018).

\section{REFERENCES}

AENOR, 2015. UNE-EN 41805:2015. Building diagnosis. Madrid. Spain.

AENOR, 2012. UNE-EN 15217:2012. Energy performance of buildings. Methods for expressing energy performance and for energy certification of buildings.

Aksoezen, M., Daniel, M., Hassler, U., Kohler, N., 2015. Building age as an indicator for energy consumption. Energy Build. 87, 74-86. https://doi.org/10.1016/j.enbuild.2014.10.074

Arumägi, E., Simson, R., Kuusk, K., Kalamees, T., 2017. Analysis of cost-optimal minimum energy efficiency requirements for buildings.

Ascione, F., Bianco, N., De Stasio, C., Mauro, G.M., Vanoli, G.P., 2015. A new methodology for cost-optimal analysis by means of the multi-objective optimization of building energy performance. Energy Build. 88, 78-90. https://doi.org/10.1016/j.enbuild.2014.11.058

Barrios-Padura, Á., Mariñas, J.C., Molina-Huelva, M., Fernández Portero, C., de Luxan, M., Fernández-Ans, P., Sabater, T., Alarcón Rubio, D., Jiménez López, I., Luna Lozano, T., Blandón González, B., Gómez de Terreros, P., González Fustegueras, M., 2015. $(\mathrm{Re})$ Programa. $(\mathrm{Re})$ habitation $+(\mathrm{Re})$ generation $+(\mathrm{Re})$ programming. The recycling and the sustainable management of the Andalusian housing stock. Management of habitable surroundings from the criteria of active aging, gender and urban habitability. Seville.

Bedir, M., Kara, E.C., 2017. Behavioral patterns and profiles of electricity consumption in $\begin{array}{llll}\text { dutch dwellings. } & \text { Energy } & \text { Build. } & 150,\end{array}$ https://doi.org/10.1016/j.enbuild.2017.06.015

Bolis, I., Morioka, S.N., Sznelwar, L.I., 2017. Are we making decisions in a sustainable way? A comprehensive literature review about rationalities for sustainable development. J. Clean. Prod. 145, 310-322. https://doi.org/10.1016/j.jclepro.2017.01.025

Cuchí, A., Sweatman, P., 2014. GTR 2014 Report. Strategy for building renovation. Keys to transform the building sector in Spain. ("Estrategia para la rehabilitación. Claves para transformar el sector de la edificación en España").

European Commission, 2018. Directive (EU) 2018/844 of the European Parliament and of the Council of 30 May 2018 amending Directive 2010/31/EU on the energy performance of buildings and Directive 2012/27/EU on energy efficiency. Official Journal of the European Union.

European Commission, 2016. An EU Strategy on Heating and Cooling (COM(2016) 51 final). European Commission, 2015a. Implementing the Energy Performance of Buildings Directive (EPBD). Featuring Country Reports. ADENE, Lisbon.

European Commission, 2015b. Population ageing in Europe. Facts, implications and policies. European Commission, 2014. Energy efficiency and its contribution to energy security and the 
2030 framework for climate and energy policy 520 .

European Commission, 2010. Directive 2010/31/EU of the European Parliament and of the Council of 19 May 2010 on the Energy Performance of Building (recast). Official Journal of the European Union.

Femenías, P., Mjörnell, K., Thuvander, L., 2018. Rethinking deep renovation: The perspective of rental housing in Sweden. J. Clean. Prod. 195, 1457-1467. https://doi.org/10.1016/j.jclepro.2017.12.282

Gamarra, A.R., Istrate, I.R., Herrera, I., Lago, C., Lizana, J., Lechón, Y., 2018. Energy and water consumption and carbon footprint of school buildings in hot climate conditions. Results from life cycle assessment. J. Clean. Prod. 195, 1326-1337. https://doi.org/10.1016/j.jclepro.2018.05.153

GBPN, 2013. What is a deep renovation definition? 237-254.

Government of Spain, 2013a. Royal decree 233/2013. Model type of Building Assessment Report (IEE). Ministry of the Presidency.

Government of Spain, 2013b. Royal decree 235/2013, 5 of April, which approves the basic procedure for the certification of building energy efficiency. Ministry of the Presidency. Spain.

Heiskanen, E., Johnson, M., Vadovics, E., 2013. Learning about and involving users in energy saving on the local level. J. Clean. Prod. 48, 241-249. https://doi.org/10.1016/j.jclepro.2012.08.019

Hermelink, A.H., Jager, D. De, Ecofys, 2016. Evaluating our future modelling: The crucial role of discount rates in European Commission energy system modelling.

Hong, T., Taylor-Lange, S.C., D’Oca, S., Yan, D., Corgnati, S.P., 2016. Advances in research and applications of energy-related occupant behavior in buildings. Energy Build. 116, 694-702. https://doi.org/10.1016/j.enbuild.2015.11.052

IDAE, 2015a. Report on regulated energy prices. January 2015.

IDAE, 2015b. Report on regulated energy prices. June 2015.

IDAE, 2011. Renewable energy plan (PER) 2011 - 2020.

IECA, 2012. National Institute of Statistics and Cartography of Andalusia. Spatial distribution of the population in Andalusia. ("Distribución espacial de la población en Andalucía").

INE, 2013. Projection of the Population of Spain in a short term, 2013-2023. ("Proyección de la Población de España a Corto plazo, 2013-2023”) National Statistics Institute, 1-9.

International Energy Agency, 2017. Energy Efficiency 2017. https://doi.org/10.1787/9789264284234-en

International Energy Agency, 2013a. Transition to Sustainable Buildings. Strategies and Opportunities to 2050. OECD/IEA. https://doi.org/10.1787/9789264202955-en

International Energy Agency, 2013b. Technology Roadmap. Energy efficient building envelopes. OECD/ IEA, France.

Kovacic, I., Summer, M., Achammer, C., 2015. Strategies of building stock renovation for ageing society. J. Clean. Prod. 88, 349-357. https://doi.org/10.1016/j.jclepro.2014.04.080

Li, H., Zhang, X., Ng, S.T., Skitmore, M., 2018. Quantifying stakeholder influence in decision/evaluations relating to sustainable construction in China - A Delphi approach. J. Clean. Prod. 173, 160-170. https://doi.org/10.1016/j.jclepro.2017.04.151

Liang, X., Peng, Y., Shen, G.Q., 2016. A game theory based analysis of decision making for green retrofit under different occupancy types. J. Clean. Prod. 137, 1300-1312. https://doi.org/10.1016/j.jclepro.2016.07.200

Lizana, J., Barrios-Padura, Á., Molina-Huelva, M., Chacartegui, R., 2016. Multi-criteria assessment for the effective decision management in residential energy retrofitting. Energy Build. 129, 284-307. https://doi.org/10.1016/j.enbuild.2016.07.043

Lizana, J., Serrano-Jimenez, A., Ortiz, C., Becerra, J.A., Chacartegui, R., 2017. Energy 
assessment methodology towards low-carbon energy schools applied to Mediterranean buildings, in: 12th Conference on Sustainable Development of Energy, Water and Environment Systems. SDEWES 2017.

Mata, É., Sasic Kalagasidis, A., Johnsson, F., 2015. Cost-effective retrofitting of Swedish residential buildings: effects of energy price developments and discount rates. Energy Effic. 8, 223-237. https://doi.org/doi.org/10.1007/s12053-014-9287-1

Ministry of Development, 2013. Basic Document DB-HE ("Ahorro de energía"), of the Technical Building Code. Spain.

Ministry of housing, 2009. Conditions of acceptance of Alternative Procedures to LIDER and CALENER. Institute for the Diversification and Saving of Energy (IDAE).

Ministry of housing, 2006. Royal decree 314/2006, March 17, by which the Technical Building Code is approved. Spain.

Perera, P., Hewage, K., Alam, M.S., Mèrida, W., Sadiq, R., 2018. Scenario-based economic and environmental analysis of clean energy incentives for households in Canada: Multi criteria decision making approach. J. Clean. Prod. 198, 170-186. https://doi.org/10.1016/j.jclepro.2018.07.014

Pombo, O., Rivela, B., Neila, J., 2016. The challenge of sustainable building renovation: Assessment of current criteria and future outlook. J. Clean. Prod. 123, 88-100. https://doi.org/10.1016/j.jclepro.2015.06.137

Prasanna, A., Mahmoodi, J., Brosch, T., Patel, M.K., 2018. Recent experiences with tariffs for saving electricity in households. Energy Policy 115, 514-522. https://doi.org/10.1016/j.enpol.2018.01.044

Serrano-Jimenez, A., Barrios-Padura, A., Molina-Huelva, M., 2017. Towards a feasible strategy in Mediterranean building renovation through a multidisciplinary approach. Sustain. Cities Soc. 32, 532-546. https://doi.org/10.1016/j.scs.2017.05.002

Serrano-Jiménez, A., Barrios-Padura, Á., Molina-Huelva, M., 2018. Sustainable building renovation for an ageing population: Decision support system through an integral assessment method of architectural interventions. Sustain. Cities Soc. 39, 144-154. https://doi.org/10.1016/j.scs.2018.01.050

Short, W., Packey, D., Holt, T., 2005. A manual for the economic evaluation of energy efficiency and renewable energy technologies. Univ. Press Pacific 2, 120. https://doi.org/NREL/TP-462-5173

Spanish National Bank, 2017. Annual Statistical Bulletin. Madrid.

Stieß, I., Dunkelberg, E., 2013. Objectives, barriers and occasions for energy efficient refurbishment by private homeowners. J. Clean. Prod. 48, 250-259. https://doi.org/10.1016/j.jclepro.2012.09.041

Tadeu, S.F., Alexandre, R.F., Tadeu, A.J.B., Henggeler, C., Simões, N.A. V, Pereira, P., 2016. A comparison between cost optimality and return on investment for energy retrofit in buildings-A real options perspective. Sustain. Cities Soc. 21, 12-25. https://doi.org/10.1016/j.scs.2015.11.002

Thuvander, L., Femenías, P., Mjörnell, K., Meiling, P., 2012. Unveiling the Process of Sustainable Renovation. Sustainability 4, 1188-1213. https://doi.org/10.3390/su4061188

Vilches, A., Barrios Padura, Á., Molina Huelva, M., 2017. Retrofitting of homes for people in fuel poverty: Approach based on household thermal comfort. Energy Policy 100, 283291. https://doi.org/10.1016/j.enpol.2016.10.016

Wallis, H., Nachreiner, M., Matthies, E., 2016. Adolescents and electricity consumption; Investigating sociodemographic, economic, and behavioural influences on electricity consumption in households. Energy Policy 94, 224-234. https://doi.org/10.1016/j.enpol.2016.03.046 